Review

\title{
The Importance of Controlling the TGF- $\beta$ Signaling Pathway in the Gastric Cancer Microenvironment
}

\author{
Jun Kinoshita, Sachio Fushida * and Tetsuo Ohta \\ 1 Department of Gastroenterological Surgery, Kanazawa University Hospital, Kanazawa, Japan; \\ junkino0416@gmail.com (J.K.); ohtat@staff.kanazawa-u.ac.jp (S.F.) \\ * Correspondence: fushida@staff.kanazawa-u.ac.jp; Tel.: +81-76-265-2362
}

\begin{abstract}
Gastric cancer is an intractable disease with a high incidence of peritoneal dissemination and obstructive symptoms (e.g. ileus, jaundice, and hydronephrosis) arising from accompanying marked fibrosis. Microenvironmental interactions between cancer cells and stromal cells are the suggested cause of the disease. Transforming growth factor (TGF- $\beta$ ) is an intriguing cytokine exhibiting dual roles in malignant disease, acting as an important mediator of cancer invasion, metastasis, and angiogenesis as well as exhibiting antitumor functions. Moreover, the TGF- $\beta$ pathway contributes to the generation of a favorable microenvironment for tumor growth and metastasis throughout the steps of carcinogenesis. Among these effects, TGF- $\beta$ induces the epithelial-to-mesenchymal transition with prometastatic functions, contributes to the conversion of stromal cells to carcinoma-associated fibroblasts, and suppresses the function of immune cells, which compromises the antitumor immune response, leading to cancer progression and stromal fibrosis. In this review, we address the role of the essential TGF- $\beta$ signaling pathway in the regulation of the activities of components of the tumor microenvironment of gastric cancer and how this contributes to tumor progression and stromal fibrosis. We then explore the potential to optimize therapy that inhibits TGF- $\beta$ signaling in the preclinical and clinical settings of gastric cancer.
\end{abstract}

Keywords: TGF- $\beta$; gastric cancer; microenvironment

\section{Introduction}

Gastric cancer is the fourth most common cancer worldwide and the second leading cause of cancer-related death [1]. Peritoneal dissemination is a critical indicator of poor prognosis and represents the most frequent metastatic pattern in gastric cancer [2]. Although clinical outcomes for patients with gastric cancer with peritoneal dissemination have improved with advances in systemic or intraperitoneal chemotherapy, or both, acceptable outcomes have not been achieved [3-6]. Peritoneal dissemination is characterized by the infiltration of cancer cells, and their proliferation is accompanied by extensive stromal fibrosis [7]. These processes contribute to the development of chemoresistance and obstructive disorders such as ileus, obstructive jaundice, and hydronephrosis, which lead to marked deterioration of health-related quality of life. Therefore, new strategies are required for the development of more effective treatment of tumor proliferation and fibrosis associated with peritoneal dissemination of gastric cancer.

Transforming growth factor- $\beta$ (TGF- $\beta$ ) is a ubiquitously expressed cytokine that mediates or regulates a wide spectrum of biological processes, including proliferation, differentiation, embryonic development, angiogenesis, wound healing, and other functions [8]. Cancer cells generally secrete larger amounts of TGF- $\beta$ compared with their normal counterparts. In early-stage tumors, the TGF- $\beta$ pathway promotes cell cycle arrest and apoptosis [9-11], while in advanced tumors; these processes positively associate with tumor aggressiveness and poor prognosis by promoting cancer cell motility, invasion, the epithelial-to-mesenchymal transition (EMT), and cell 
stemness [12]. These findings reveal that the TGF- $\beta$ pathway enhances or inhibits the malignant phenotype, and this functional switch is called the "TGF- $\beta$ paradox" [13]. In contrast, at the level of the microenvironment, the TGF- $\beta$ pathway contributes to the generation of an advantageous environment for tumor invasion and metastasis throughout all steps of carcinogenesis. Therefore, controlling the activity of the TGF- $\beta$ signaling pathway to develop more effective cancer therapy may be considered primarily as a microenvironment-targeted strategy. Although numerous studies describe the role of TGF- $\beta$ in the initiation of cancer, highly incisive investigations are required to better understand the function of TGF- $\beta$ in the tumor microenvironment of gastric cancer.

Our goal was to summarize and discuss the state-of-the-art knowledge of the role of TGF- $\beta$ in gastric cancer, with special focus on the effects of this cytokine on cells in the cancer microenvironment. Furthermore, we consider how therapeutic strategies aimed at inhibiting TGF- $\beta$ signaling can impair the peritoneal dissemination of gastric cancer.

\section{TGF- $\beta$ pathway}

Numerous excellent reviews extensively cover TGF- $\beta$ signal transduction [14-17]. Briefly, the TGF- $\beta$ superfamily comprises more than 30 different members, including the TGF- $\beta$ s (comprising the three highly homologous isoforms TGF- $\beta 1$, TGF- $\beta 2$, and TGF- $\beta$ ), activins, NODAL, bone morphogenetic proteins (BMPs), growth and differentiation factors (GDFs), and anti-Mullerian hormone (AMH) [18]. TGF- $\beta$ s are synthesized as dimeric prohormones and then secreted into the extracellular matrix (ECM). The canonical TGF- $\beta / S$ mad signaling cascade is initiated when a TGF- $\beta /$ BMP ligand binds to a type II serine/threonine kinase receptor; and type II serine/threonine kinase receptors, in turn, recruit and phosphorylate type I receptors [19]. Phosphorylated type I receptors subsequently produce a signal by phosphorylating RSmad, which forms a complex with Smad4. TGF- $\beta$ ligands transmit the signal through Smad2 and Smad3, whereas BMP signaling leads to phosphorylation of Smad1, Smad5, and Smad8 [20]. Activated Smad complexes are transported into the nucleus where they act together with coactivators or corepressors to regulate target gene transcription. Noncanonical TGF- $\beta$ signaling activates other signaling pathways such as the phosphoinositide 3-kinase-Akt-mTOR pathway, the p38 and Jun N-terminal kinase (JNK) mitogen-activated protein kinase (MAPK) pathways, the small GTPase RhoA and Rac/Cdc42 pathways, and the Ras-Erk pathway. The activation of these pathways enhances tumor growth after canonical TGF- $\beta /$ Smad signaling is interrupted [21,22].

\section{Sources of TGF- $\beta$ in gastric cancer}

\section{3-1 The mechanism of secretion of TGF- $\beta$ by gastric cancer cells}

The sources of TGF- $\beta$ in tumors vary and include the cancer cells themselves as well as cells of the tumor stroma, with each source leading to context-dependent functional consequences. As indicated above, cancer cells generally secrete larger amounts of TGF- $\beta$ than their normal counterparts to regulate their own activities within the tumor mass in an autocrine or paracrine fashion [20]. Interestingly, Okazaki et al. demonstrated that the mechanism of secretion of TGF- $\beta$ by gastric cancer cells involves a local angiotensin II/AT1 receptor-generating system in tumor tissue (Figure 1) [24].

The microenvironment of gastric cancer is approximately $\mathrm{pH} 5.5$ under hypoxic conditions. Gastric cancer cells express trypsinogen that converts to trypsin at pH 5.5 [25]. Furthermore, mast cells that migrate into gastric cancer tissues express tryptase. Trypsin and tryptase generate angiotensin II from circulating angiotensinogen in the absence of angiotensin converting enzyme (ACE) in acidic tissues. Indeed, there is a sharp contrast between tumor tissues and normal regions with respect to the concentrations of angiotensin II in gastric cancer tissue [26]. The angiotensin II type I receptor (AT1R) is highly expressed in gastric cancer cell lines and gastric cancer tissues. 
Angiotensin II has the potential to impair apoptosis induced by $\mathrm{NF}-\kappa \mathrm{B}$ activation and overexpression and promotes tumor proliferation induced by ERK1/2 activation [26]. Moreover, angiotensin II induces the expression of the TGF- $\beta$ activator thrombospondin- 1 via the AT1 receptor, thereby mediating activation of latent TGF- $\beta \quad[27,28]$. The angiotensin II/AT1 receptor axis contributes to fibrosis through endogenous production of TGF- $\beta 1$ in chronic renal disease $[29,30]$. Okazaki et al. demonstrated that treatment of MKN45 cells with angiotensin II increases the expression of TGF- $\beta 1$, whereas pretreatment of cells with angiotensin receptor blockers (ARBs) effectively inhibit this response [24].

\section{3-2. Secretion of TGF- $\beta$ in the tumor microenvironment}

The sustained release of local TGF- $\beta$ levels is appropriate to maintain normal tissue homeostasis. However, the local secretion of TGF- $\beta$ from stromal cells and platelets is increased to facilitate tissue repair [31,32]. A similar situation is commonly found in malignant tumors where TGF- $\beta$ is initially secreted in the microenvironment to control proliferation and cancer progression. Tumors are infiltrated by stromal cells such as fibroblasts, leukocytes, mast cells, macrophages, bone-marrow derived endothelial cells, and mesenchymal and myeloid precursor cells. The presence of these tumor-infiltrating cells is a major source of TGF- $\beta$ and is thus a suspected source of the accumulation of TGF- $\beta 1$ at the invasion front of the tumor [33]. Furthermore, the platelet aggregation-inducing factor podoplanin induces the EMT of tumor cells by increasing the release of TGF- $\beta$ from platelets [34]. In vitro and in vivo analyses reveal that the podoplanin-mediated EMT increases invasiveness, and the tumor cells become resistant to chemotherapy, which is associated with poor prognosis. Local release of TGF- $\beta$ produces a tumor microenvironment that is conducive to tumor growth, invasion, and metastasis [35].

The TGF- $\beta$ signaling pathway influences microenvironment fibrosis, angiogenesis, and immune cell infiltration. Activation of the TGF- $\beta$ pathway induces the EMT, suppressing the function of immune cells that mediate the immune response to tumors, the conversion of fibroblasts to myofibroblasts, and the overproduction of the extracellular matrix, thereby contributing to the maintenance of a favorable tumor microenvironment.

\section{The EMT}

Abundant evidence reveals the importance of the EMT, in which epithelial cells are transformed into cells with mesenchymal phenotypes characterized by loss of cellular polarity and adhesion as well as enhanced invasive and migratory properties. The components of the complex tumor microenvironment, including tumor stromal cells and cellular factors, modulate the growth of cancer cells and regulate their malignant phenotype through EMT processes induced by diverse intracellular signaling pathways such as those that involve Wnt and receptor tyrosine kinases (RTKs). Better characterized examples of such pathways include Snail [36], Slug [37], zinc-finger E-box binding homeobox 1 (ZEB1/SEF1) [38], zinc-finger E-box binding homeobox 2/Smad interacting protein 1 (ZEB2/SIP1) [39], Twist [40], high mobility group AT-hook 2 (HMGA 2) [41], and forkhead box protein C2 (FOXC2) [42]. Furthermore, an overactive TGF- $\beta$-TGF- $\beta$ R-Smad2 signaling axis could contribute to the establishment of an EMT phenotype by maintaining the epigenetic silencing of epithelial genes [43]. Other signaling pathways are implicated in the TGF- $\beta$-induced EMT, including Erk, PI3K/Akt, RhoA, p38-MAPK, and cofilin [23,38,44].

Induction of the EMT is a major mechanism by which TGF- $\beta$ promotes cell motility, invasiveness, and metastasis of cancer cells [45]. The EMT significantly enhances intravasation of carcinoma-in situ cells through the basement membrane, survival in the circulation, extravasation at distal tissues, and formation of micrometastases in secondary organs [40,46,47]. Furthermore, the EMT is a key driver of gastric cancer progression and induces the migration of gastric cancer cells 
enabling them to reach their metastatic niche through the lymphatic and blood circulatory systems. The EMT phenotype correlates with an advanced stage of gastric cancer [48].

\section{Cancer-associated fibroblasts (CAFs) in the microenvironment of gastric cancer}

The EMT generates tumor stromal cells, particularly CAFs, which are the most prominent components of the tumor microenvironment in tumor tissues. CAFs secrete factors such as EGF, IGF-1, PDGF, FGF, MMP, and type I collagen that favor malignant progression [49-51], which lead to the deposition of the ECM, the promotion of angiogenesis and the EMT, and the enhancement of proliferation, immunotolerance, and resistance to chemotherapy (Figure 2) [52,53]. These CAF functions play important roles in cancer progression and promote tumor cell invasion and metastasis. CAFs can be isolated from breast, prostate, pancreatic, cholangiocarcinoma, and gastric cancers, which are characterized by abundant fibrotic stroma. Conversely, CAFs are relatively rare in brain, renal, and ovarian cancers [44, 54-61]. A common theory of the origin of CAFs implicates resident tissue fibroblasts where TGF- $\beta$ may promote the differentiation of fibroblasts to activated fibroblasts [62], which involves chloride intracellular channel 4 (CLIC4) [63]. Genetic ablation of CLIC4 in primary fibroblasts decreases TGF- $\beta$-induced expression of $\alpha$-SMA and other markers, including ECM components.

In turn, CAFs secrete large amounts of TGF- $\beta$, which amplify the stromal reaction and induce an autocrine signaling loop that maintains the differentiation of fibroblasts into myofibroblasts [64]. Thus, TGF- $\beta$ is a key mediator of this dialogue between CAFs and cancer cells. The CAF phenotype is generally distinct from that of normal fibroblasts. For example, Ishimoto et al. reported that the increased expression of RHBDF2, which regulates TGF- $\beta 1$ signaling is observed in CAFs isolated from human diffuse gastric cancer compared with nonmalignant fibroblasts [65]. There are several theories that propose alternative origins of CAFs, and this topic is still under debate. For example, bone marrow-derived mesenchymal stem cells, hematopoietic stem cells, epithelial cells that undergo the EMT, and endothelial cells that undergo the endothelial-mesenchymal transition are considered possible predecessors of CAFs (Figure 2). In gastric cancer, human peritoneal mesothelial cells (HPMCs) transform into myofibroblast-like cells following exposure to TGF- $\beta$, and these cells contribute to stromal fibrosis in a mouse xenograft model when coinoculated with MKN45 gastric cancer cells [66]. Moreover, in vivo experiment demonstrate that bone marrow-derived cells (fibrocytes) migrate and enhance tumor proliferation and fibrosis via the SDF-1/CXCR4 system [67]. These results suggest that HPMCs and fibrocytes have a latent ability to function as CAFs in the gastric cancer tumor microenvironment, which facilitates the development of fibrosis in the primary tumor and peritoneal dissemination (Figure 2).

\section{Effect of TGF- $\beta$ on immune cells}

TGF- $\beta$ is considered one of the most important regulators of proliferation and differentiation of immune cells deposited in a tumor microenvironment. Specifically, TGF- $\beta$ affects the function of natural killer cells (NK cells), CD4+ and 8+ T cells, macrophages, neutrophils, dendritic mast cells, and B cells. Cytotoxic T lymphocytes (CD8+ CTLs) are required to control tumor progression. CD4+CD25+Foxp3+ regulatory $\mathrm{T}$ cells (Treg cells) cells are a specialized $\mathrm{T}$ cell subpopulation that suppresses the activation of the immune system [68]. In tumors, natural and adaptive Treg cell concentrations increase in tumor sites and contribute to tumor-induced immunosuppression by suppressing the proliferation and function of CTLs [69]. TGF- $\beta$ has the capacity to induce FoxP3 gene expression, which drives the phenotypic conversion of naïve $\mathrm{T}$ cells to Treg cells [70,71].

Deng et al. found that hypoxia in gastric cancer induces Treg cells in tumors by up-regulating the expression of TGF- $\beta 1$. Lu et al. found that gastric cancer-induced infiltration of Treg cells predicts poor prognosis of patients with gastric cancer and that some of these Treg cells are converted by TGF- $\beta$ produced by tumor cells [72]. In B-cells, TGF- $\beta$ controls the expression of 
immunoglobulins, surface receptors, and major histocompatibility complex type II proteins, which are direct markers of B-cell maturation and differentiation [73]. TGF- $\beta$ inhibits the proper maturation of NK cells, which then lose their ability to recognize nonself antigens, an important process required for the clearance of cancer cells [74]. Furthermore, TGF- $\beta$ negatively regulates the ability of dendritic cells to present foreign antigens [75]. Proliferation of the monocyte-macrophage lineage cells is suppressed mainly by TGF- $\beta$ ligands $[76,77]$.

Two types of macrophages (phenotypes M1 and M2) are present in the tumor microenvironment. Classically activated M1 macrophages can phagocytose tumor cells. Therefore, these macrophages are involved in the immune response against infection and tumor cell invasion. M1 macrophages play a critical role in cellular immunity against cancer. Alternatively activated M2 macrophages perform a function distinct from that of M1 macrophages. M2 macrophages are the most abundant in tumors and are known as tumor-associated macrophages (TAMs) [78], which can facilitate tumor cell proliferation, angiogenesis, and tissue remodeling. Interestingly, Yamaguchi et al. reported that gastric cancer patients with peritoneal dissemination have significantly higher numbers of TAMs with the M2 phenotype in ascites compared with those without peritoneal dissemination [79]. TGF- $\beta$ activation can induce a shift of polarization from antitumor M1 to M2 TAMs (Figure 2) [80]. Furthermore, TGF- $\beta$ induces an N2 neutrophil phenotype, which, as well as macrophages, reduces effector function and increases the secretion of inflammatory cytokines [81]. These combined immunosuppressive effects of TGF- $\beta$ compromise the ability of the host to resist tumor progression and thus serve as a barrier to immunotherapy.

\section{Clinical Outlook: Targeting Stromal Modulators of TGF- $\beta$ in Gastric Cancer}

Pharmacological inhibition of TGF- $\beta$ has been used in preclinical and clinical studies as a strategy to directly hinder tumor progression or modify the tumor microenvironment. Diverse therapeutic agents block the TGF- $\beta$ pathway, including soluble receptors and antisense oligonucleotides against TGF- $\beta$ ligands, neutralizing antibodies, and small molecule inhibitors of TGFBRI or II receptors [82]. These TGF- $\beta$ inhibitors may have limited effects on cancer cells and exert their antitumor activities mainly by affecting TGF- $\beta$-responsive cells (fibroblastic, endothelial, and immune cells) in the tumor microenvironment, because TGF- $\beta$ signaling is altered or absent from cancer cells. Therefore, TGF- $\beta$ inhibition may be considered to primarily maintain the homeostasis of the tumor microenvironment by down-regulating stromal stimulation by excess TGF $\beta$ production by tumor and tumor-related tissues, with an indirect effects on cancer cells.

Numerous studies of preclinical tumor models show that TGF- $\beta$ inhibitors elicit antitumorigenic effects on several malignancies through microenvironmental changes [35]. Shinto et al. used a mouse model of orthotopically grafted gastric cancer to show that an inhibitor of TGF- $\beta$ receptor I phosphorylation (Ki26894) suppresses the growth interactions between human scirrhous gastric cancer cells (OCUM-2MLN) and orthotopic fibroblasts and that combination therapy with S1 decreases lymph node metastasis more effectively than S-1 alone [83]. Miao et al. employed mice inoculated with a gastric cancer cell line (SGC-7901) to show that a TGF- $\beta$ receptor inhibitor (SB-431542) reduces SGC-7901-induced HPMC fibrosis and attenuates the formation of peritoneal dissemination and peritoneal fibrosis [84]. Furthermore, the outcomes of several Phase I and Phase II clinical trials show that therapeutics targeted to TGF- $\beta$ are safe and efficacious for patients with colorectal, hepatocellular, and non-small cell lung cancer as well as patients with pancreatic ductal carcinoma and other cancers. Many of these trials are in progress [16]. In contrast, clinical trials of TGF- $\beta$ inhibitors targeting gastric cancer have not been implemented. However, large clinical trial must take into account the ubiquitous expression of TGF- $\beta 1$ and its receptors and their important roles in maintaining the homeostasis and specialized functions of normal tissues. Therefore, this is a major conceptual problem with the long-term clinical use of these agents, because there is a high likelihood of adverse side effects and the induction of new cancers and autoimmune diseases. 
Certain drugs are widely used in clinical settings that inhibit the TGF- $\beta$ signaling system. In vivo studies show that repositioning the antihypertensive, angiotensin receptor blocker (ARB) losartan, used at doses that do not affect blood pressure, reduces the expression of TGF- $\beta$ and decreases the production of stromal collagen and hyaluronan production. Furthermore, losartan reduces interstitial fluid pressure by decreasing the concentrations of ECM components, which contribute to improving the delivery and efficacy of chemotherapeutic agents in orthotopic murine models of orthotropic breast and pancreatic cancer [85]. Okazaki et al. found that the ARB candesartan reduces TGF- $\beta$ expression and stromal fibrosis through the suppression of an EMT-like change of HPMCs in a mouse xenograft model of gastric cancer [24].

Paclitaxel (PTX), derived from the bark of the Pacific yew Taxus brevifolia, is a standard second-line agent for treating advanced gastric cancer. PTX improves intestinal stenosis caused by stromal fibrosis associated with the progression of peritoneal dissemination [86]. Tsukada et al. found that a low dose of PTX suppresses the TGF- $\beta 1$-induced EMT of HPMCs by inhibiting Smad2 phosphorylation and decreases stromal fibrosis in human peritoneal cells [87].

Protein-bound polysaccharide K (PSK) is isolated and purified from the cultured mycelium of the Basidiomycete Coriolus versicolor [88]. PSK is considered a biological response modifier and was approved for use in Japan in combination with chemotherapy to prolong the survival of patients with gastric or colorectal cancer. PSK may inhibit TGF- $\beta$ signaling through suppression of TGF- $\beta$ production by binding TGF- $\beta$ and through acting on TGF- $\beta$ receptors [89-91]. Ono et al. found that PSK suppresses Smad2 phosphorylation, resulting in the inhibition of the EMT in the colorectal cancer cell line SW837 [92]. Shinbo et al. found that PSK inhibits the EMT-like change of HPMCs in response to TGF- $\beta$ signaling in vitro as well as the subsequent induction of tumor fibrosis by coinoculation of the gastric cancer cell line OCUM-2MD3 with HPMCs in a mouse xenograft model [93].

Finally, N-[3,4-dimethoxycinnamonyl]-anthranilic acid (tranilast), an orally administered drug with low toxicity, has been used clinically as an antiallergic and antifibrotic agent that inhibits the growth of fibroblasts in keloid tissue [94]. Studies of animal models show that tranilast prevents tissue fibrosis by attenuating local TGF- $\beta 1$ expression and subsequent TGF- $\beta$-induced collagen deposits in several organs in patients with nonmalignant disorders such as diabetic cardiomyopathy and chronic cyclosporine nephrotoxicity $[95,96]$. In a study of gastric cancer, Saito et al. found that tranilast suppresses the TGF- $\beta /$ Smad pathway by inhibiting Smad2 phosphorylation in HPMCs treated with TGF- $\beta 1$ and significantly decreases growth and stromal fibrosis in a mouse xenograft model of fibrosis. It is well known that drug repositioning is the application of drugs and other compounds to treat new indications and has been growing in importance during the last few years, accompanied by an increasing number of drugs under development. All of these antihypertensive, anticancer, and antiallergy agents have been widely used in clinical practice without serious side effects and may potentially be safe when administered in combination with TGF- $\beta$ as tumor microenvironment targeting agents that inhibit gastric cancers.

\section{Conclusions}

TGF- $\beta$ signaling is a fundamental pathway required for normal development and the functions of mature cells. TGF- $\beta$ ligands are widely expressed in all tissues. Moreover, TGF- $\beta$ is considered a central player during cancer development and progression. The present review explores the role of the TGF- $\beta$ pathway in the microenvironment of gastric cancer. It is evident that cross-talk between different cells in a tumor microenvironment is essential for cancer progression and that TGF- $\beta$ is a potent regulator of this cross-talk. TGF- $\beta$ regulates tumor progression through mutual interactions between various components of the microenvironment such as fibroblasts, HPMCs, stromal cells, and immune cells A special role is recognized for TGF- $\beta$-activated CAFs, which represent one of the 
most abundant stromal cell types in virtually all solid tumors. TGF- $\beta$-activated CAFs are emerging as a new target for biological therapies of patients with gastric cancer.

It is promising that many anti-TGF- $\beta$ agents are clinically approved for other diseases (e.g. ARBs, PTX, PSK, tranilast). Repositioning of these drugs can lead to more effective anticancer therapies. Furthermore, the recent development of TGF- $\beta$ gene expression prognostic tools and TGF- $\beta$-response biomarkers may provide the means to select patients for anti-TGF- $\beta$ intervention to assess effective pharmacological targeting of this pathway. Analysis of the TGF- $\beta$ signaling pathway in preclinical animal models and human samples has contributed much needed clarity to the role and relevance of TGF- $\beta$ in human gastric cancer.

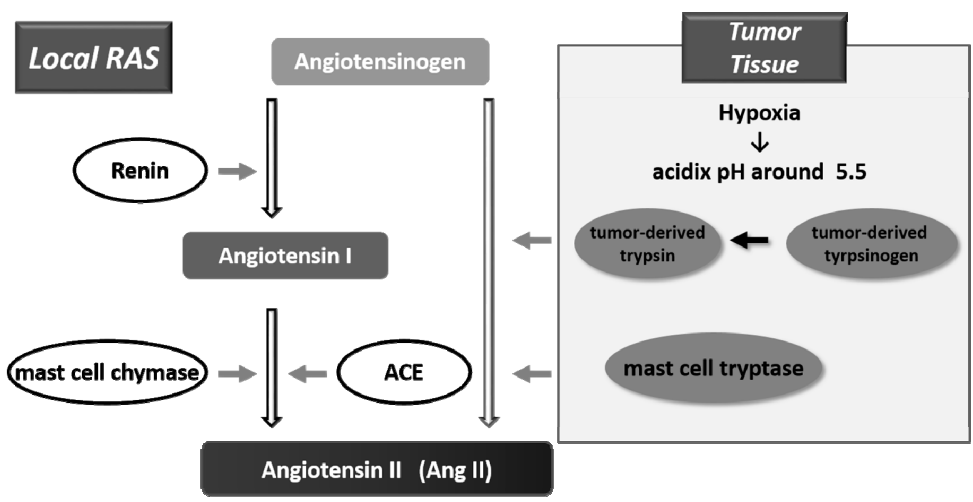

(a)

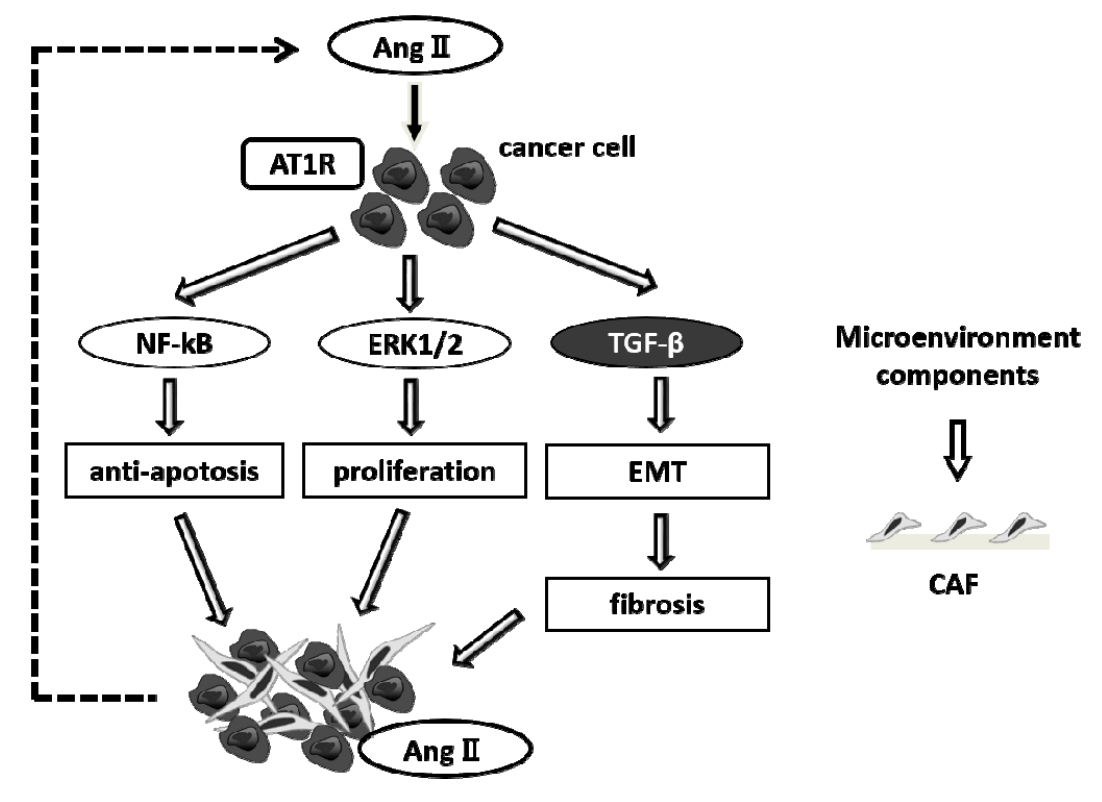

(b)

Figure 1. (a) Local angiotensin II generating system in gastric cancer tissue. RAS: renin-angiotensin system, ACE: angiotensin converting enzyme; (b) Mechanism of cellular proliferation and stromal fibrosis through angiotensin II/AT1 axis in gastric cancer. AngII: Angiotensin II, AT1R: Angiotensin II type 1 receptor, EMT: epithelial-mesenchymal transition, $\mathrm{CAF}$, cancer-associated fibroblast 


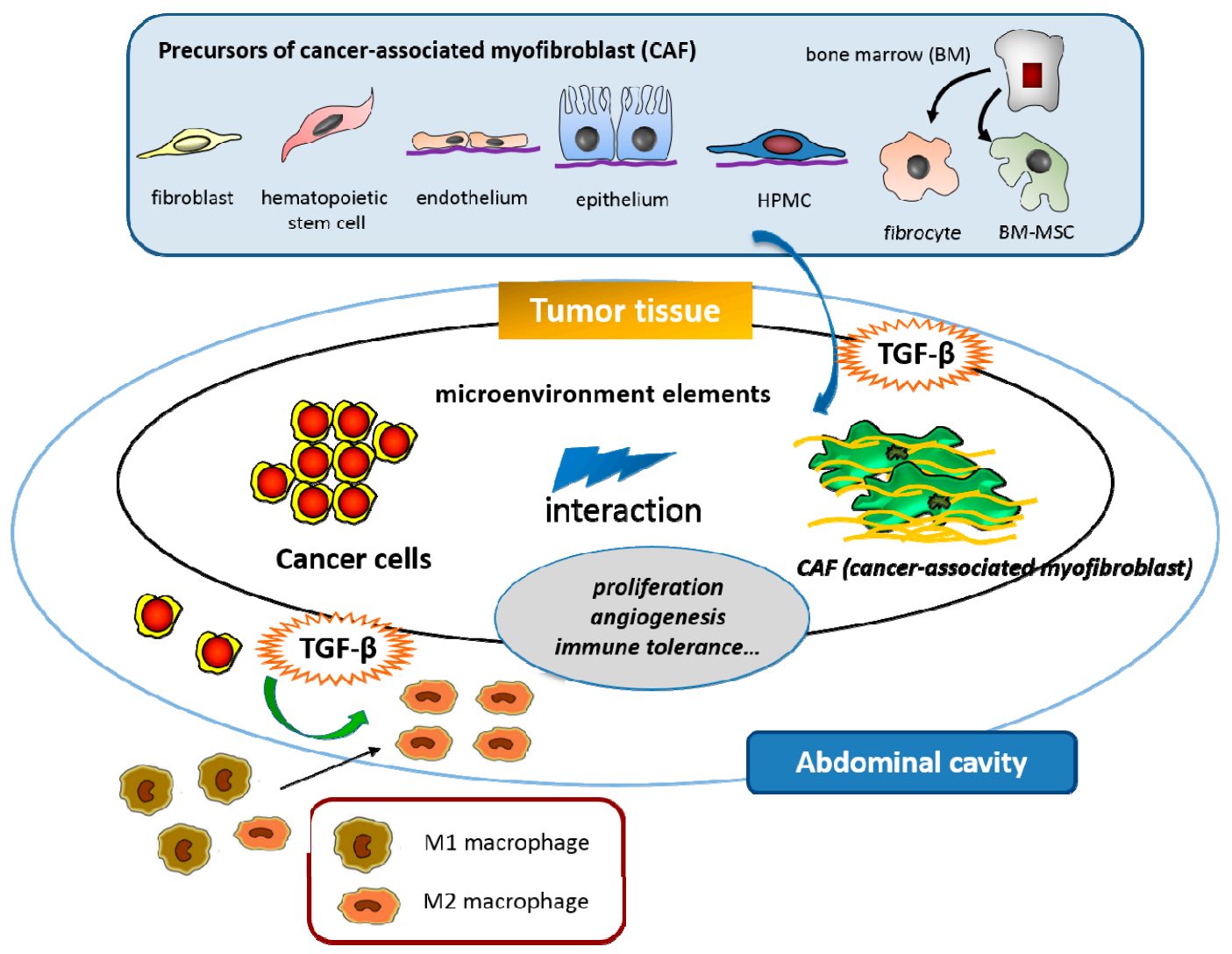

Figure 2. The regulation of TGF- $\beta$ by the components of the microenvironment of gastric cancer.

Acknowledgments: This work was supported by JSPS KAKENHI Grant Numbers JP22591451 and JP25462015 to Sachio Fushida. This study was supported by the Department of Surgical Oncology, Osaka City University, Graduate School of Medicine, Abeno-ku, Osaka 545-8585, Japan. We thank Professor Hirakawa and Dr. Yashiro for providing OCUM-2MD3, a cell line derived from a human scirrhous gastric cancer with high peritoneal seeding activity.

Conflicts of Interest: The authors declare no conflict of interest.

\section{Abbreviations}

TGF- $\beta \quad$ Transforming growth factor- $\beta$

EMT Epithelial-to-mesenchymal transition

CAFs Cancer-associated fibroblasts

ECM Extracellular matrix

AT1R Angiotensin II type I receptor

HPMCs Human peritoneal mesothelial cells

ARB Angiotensin receptor blocker

NK cells Natural killer cells

Treg cells Regulatory T cells

TAMs Tumor associated macrophages

PTX Paclitaxel

PSK Protein-bound polysaccharide K

\section{References}

1. Ferlay, J.; Soerjomataram, I.; Dikshit, R.; Eser, S.; Mathers, C.; Rebelo, M.; Parkin, D.M.; Forman, D.; Bray, F. Cancer incidence and mortality worldwide: Sources, methods and major patterns in globocan 2012. International journal of cancer 2015, 136, E359-386.

2. Maruyama, K.; Kaminishi, M.; Hayashi, K.; Isobe, Y.; Honda, I.; Katai, H.; Arai, K.; Kodera, Y.; Nashimoto, A. Gastric cancer treated in 1991 in japan: Data analysis of nationwide registry. Gastric Cancer 2006, 9, 
51-66.

3. Fushida, S.; Kinoshita, J.; Kaji, M.; Hirono, Y.; Goda, F.; Yagi, Y.; Oyama, K.; Sudo, Y.; Watanabe, Y.; Fujimura, T. Phase i/ii study of intraperitoneal docetaxel plus s-1 for the gastric cancer patients with peritoneal carcinomatosis. Cancer chemotherapy and pharmacology 2013, 71, 1265-1272.

4. Fushida, S.; Kinoshita, J.; Yagi, Y.; Funaki, H.; Kinami, S.; Ninomiya, I.; Fujimura, T.; Nishimura, G.; Kayahara, M.; Ohta, T. Dual anti-cancer effects of weekly intraperitoneal docetaxel in treatment of advanced gastric cancer patients with peritoneal carcinomatosis: A feasibility and pharmacokinetic study. Oncology reports 2008, 19, 1305-1310.

5. Koizumi, W.; Narahara, H.; Hara, T.; Takagane, A.; Akiya, T.; Takagi, M.; Miyashita, K.; Nishizaki, T.; Kobayashi, O.; Takiyama, W., et al. S-1 plus cisplatin versus s-1 alone for first-line treatment of advanced gastric cancer (spirits trial): A phase iii trial. The Lancet. Oncology 2008, 9, 215-221.

6. Shirao, K.; Boku, N.; Yamada, Y.; Yamaguchi, K.; Doi, T.; Goto, M.; Nasu, J.; Denda, T.; Hamamoto, Y.; Takashima, A., et al. Randomized phase iii study of 5-fluorouracil continuous infusion vs. Sequential methotrexate and 5-fluorouracil therapy in far advanced gastric cancer with peritoneal metastasis (jcog0106). Japanese journal of clinical oncology 2013, 43, 972-980.

7. Yashiro, M.; Chung, Y.S.; Nishimura, S.; Inoue, T.; Sowa, M. Fibrosis in the peritoneum induced by scirrhous gastric cancer cells may act as "soil" for peritoneal dissemination. Cancer 1996, 77, 1668-1675.

8. Morikawa, M.; Derynck, R.; Miyazono, K. Tgf-beta and the tgf-beta family: Context-dependent roles in cell and tissue physiology. Cold Spring Harbor perspectives in biology 2016, 8.

9. Drabsch, Y.; ten Dijke, P. Tgf-beta signalling and its role in cancer progression and metastasis. Cancer metastasis reviews 2012, 31, 553-568.

10. Jakowlew, S.B. Transforming growth factor-beta in cancer and metastasis. Cancer metastasis reviews 2006, 25, 435-457.

11. Tian, M.; Neil, J.R.; Schiemann, W.P. Transforming growth factor-beta and the hallmarks of cancer. Cellular signalling 2011, 23, 951-962.

12. Inman, G.J. Switching tgfbeta from a tumor suppressor to a tumor promoter. Current opinion in genetics $\mathcal{E}$ development 2011, 21, 93-99.

13. Wendt, M.K.; Tian, M.; Schiemann, W.P. Deconstructing the mechanisms and consequences of tgf-beta-induced emt during cancer progression. Cell and tissue research 2012, 347, 85-101.

14. Huse, M.; Muir, T.W.; Xu, L.; Chen, Y.G.; Kuriyan, J.; Massague, J. The tgf beta receptor activation process: An inhibitor- to substrate-binding switch. Molecular cell 2001, 8, 671-682.

15. Kretzschmar, M.; Massague, J. Smads: Mediators and regulators of tgf-beta signaling. Current opinion in genetics $\mathcal{E}$ development 1998, 8, 103-111.

16. Neuzillet, C.; Tijeras-Raballand, A.; Cohen, R.; Cros, J.; Faivre, S.; Raymond, E.; de Gramont, A. Targeting the tgfbeta pathway for cancer therapy. Pharmacology $\mathcal{E}$ therapeutics 2015, 147, 22-31.

17. Padua, D.; Massague, J. Roles of tgfbeta in metastasis. Cell research 2009, 19, 89-102.

18. Wakefield, L.M.; Hill, C.S. Beyond tgfbeta: Roles of other tgfbeta superfamily members in cancer. Nature reviews. Cancer 2013, 13, 328-341.

19. Attisano, L.; Carcamo, J.; Ventura, F.; Weis, F.M.; Massague, J.; Wrana, J.L. Identification of human activin and tgf beta type i receptors that form heteromeric kinase complexes with type ii receptors. Cell 1993, 75 , 671-680.

20. Massague, J. How cells read tgf-beta signals. Nature reviews. Molecular cell biology 2000, 1, 169-178.

21. Mu, Y.; Gudey, S.K.; Landstrom, M. Non-smad signaling pathways. Cell and tissue research 2012, 347, 11-20.

22. Zhang, Y.E. Non-smad pathways in tgf-beta signaling. Cell research 2009, 19, 128-139.

23. Derynck, R.; Akhurst, R.J.; Balmain, A. Tgf-beta signaling in tumor suppression and cancer progression. Nature genetics 2001, 29, 117-129.

24. Okazaki, M.; Fushida, S.; Harada, S.; Tsukada, T.; Kinoshita, J.; Oyama, K.; Tajima, H.; Ninomiya, I.; Fujimura, T.; Ohta, T. The angiotensin ii type 1 receptor blocker candesartan suppresses proliferation and fibrosis in gastric cancer. Cancer letters 2014, 355, 46-53.

25. Arakawa, K.; Maruta, H. Ability of kallikrein to generate angiotensin ii-like pressor substance and a proposed 'kinin-tensin enzyme system'. Nature 1980, 288, 705-706.

26. Kinoshita, J.; Fushida, S.; Harada, S.; Yagi, Y.; Fujita, H.; Kinami, S.; Ninomiya, I.; Fujimura, T.; Kayahara, M.; Yashiro, M., et al. Local angiotensin ii-generation in human gastric cancer: Correlation with tumor progression through the activation of erk1/2, nf-kappab and survivin. International journal of oncology 2009, 


\section{4, 1573-1582.}

27. Chua, C.C.; Hamdy, R.C.; Chua, B.H. Regulation of thrombospondin-1 production by angiotensin ii in rat heart endothelial cells. Biochimica et biophysica acta 1997, 1357, 209-214.

28. Naito, T.; Masaki, T.; Nikolic-Paterson, D.J.; Tanji, C.; Yorioka, N.; Kohno, N. Angiotensin ii induces thrombospondin-1 production in human mesangial cells via p38 mapk and jnk: A mechanism for activation of latent tgf-beta1. American journal of physiology. Renal physiology 2004, 286, F278-287.

29. Carvajal, G.; Rodriguez-Vita, J.; Rodrigues-Diez, R.; Sanchez-Lopez, E.; Ruperez, M.; Cartier, C.; Esteban, V.; Ortiz, A.; Egido, J.; Mezzano, S.A., et al. Angiotensin ii activates the smad pathway during epithelial mesenchymal transdifferentiation. Kidney international 2008, 74, 585-595.

30. Wolf, G. Renal injury due to renin-angiotensin-aldosterone system activation of the transforming growth factor-beta pathway. Kidney international 2006, 70, 1914-1919.

31. Grande, J.P. Role of transforming growth factor-beta in tissue injury and repair. Proceedings of the Society for Experimental Biology and Medicine. Society for Experimental Biology and Medicine (New York, N.Y.) 1997, $214,27-40$.

32. Singer, A.J.; Clark, R.A. Cutaneous wound healing. The New England journal of medicine 1999, 341, 738-746.

33. Yang, L.; Huang, J.; Ren, X.; Gorska, A.E.; Chytil, A.; Aakre, M.; Carbone, D.P.; Matrisian, L.M.; Richmond, A.; Lin, P.C., et al. Abrogation of tgf beta signaling in mammary carcinomas recruits gr- $1+\mathrm{cd} 11 \mathrm{~b}+$ myeloid cells that promote metastasis. Cancer cell 2008, 13, 23-35.

34. Takemoto, A.; Okitaka, M.; Takagi, S.; Takami, M.; Sato, S.; Nishio, M.; Okumura, S.; Fujita, N. A critical role of platelet tgf-beta release in podoplanin-mediated tumour invasion and metastasis. Scientific reports 2017, 7, 42186.

35. Pickup, M.; Novitskiy, S.; Moses, H.L. The roles of tgfbeta in the tumour microenvironment. Nature reviews. Cancer 2013, 13, 788-799.

36. Cano, A.; Perez-Moreno, M.A.; Rodrigo, I.; Locascio, A.; Blanco, M.J.; del Barrio, M.G.; Portillo, F.; Nieto, M.A. The transcription factor snail controls epithelial-mesenchymal transitions by repressing e-cadherin expression. Nature cell biology 2000, 2, 76-83.

37. Savagner, P.; Yamada, K.M.; Thiery, J.P. The zinc-finger protein slug causes desmosome dissociation, an initial and necessary step for growth factor-induced epithelial-mesenchymal transition. The Journal of cell biology 1997, 137, 1403-1419.

38. Eger, A.; Aigner, K.; Sonderegger, S.; Dampier, B.; Oehler, S.; Schreiber, M.; Berx, G.; Cano, A.; Beug, H.; Foisner, R. Deltaef1 is a transcriptional repressor of e-cadherin and regulates epithelial plasticity in breast cancer cells. Oncogene 2005, 24, 2375-2385.

39. Comijn, J.; Berx, G.; Vermassen, P.; Verschueren, K.; van Grunsven, L.; Bruyneel, E.; Mareel, M.; Huylebroeck, D.; van Roy, F. The two-handed e box binding zinc finger protein sip1 downregulates e-cadherin and induces invasion. Molecular cell 2001, 7, 1267-1278.

40. Yang, J.; Mani, S.A.; Donaher, J.L.; Ramaswamy, S.; Itzykson, R.A.; Come, C.; Savagner, P.; Gitelman, I.; Richardson, A.; Weinberg, R.A. Twist, a master regulator of morphogenesis, plays an essential role in tumor metastasis. Cell 2004, 117, 927-939.

41. Thuault, S.; Valcourt, U.; Petersen, M.; Manfioletti, G.; Heldin, C.H.; Moustakas, A. Transforming growth factor-beta employs hmga2 to elicit epithelial-mesenchymal transition. The Journal of cell biology 2006, 174, 175-183.

42. Mani, S.A.; Yang, J.; Brooks, M.; Schwaninger, G.; Zhou, A.; Miura, N.; Kutok, J.L.; Hartwell, K.; Richardson, A.L.; Weinberg, R.A. Mesenchyme forkhead 1 (foxc2) plays a key role in metastasis and is associated with aggressive basal-like breast cancers. Proceedings of the National Academy of Sciences of the United States of America 2007, 104, 10069-10074.

43. Papageorgis, P.; Lambert, A.W.; Ozturk, S.; Gao, F.; Pan, H.; Manne, U.; Alekseyev, Y.O.; Thiagalingam, A.; Abdolmaleky, H.M.; Lenburg, M., et al. Smad signaling is required to maintain epigenetic silencing during breast cancer progression. Cancer research 2010, 70, 968-978.

44. Yang, J.; Weinberg, R.A. Epithelial-mesenchymal transition: At the crossroads of development and tumor metastasis. Developmental cell 2008, 14, 818-829.

45. Deckers, M.; van Dinther, M.; Buijs, J.; Que, I.; Lowik, C.; van der Pluijm, G.; ten Dijke, P. The tumor suppressor smad4 is required for transforming growth factor beta-induced epithelial to mesenchymal transition and bone metastasis of breast cancer cells. Cancer research 2006, 66, 2202-2209.

46. Kang, Y.; Massague, J. Epithelial-mesenchymal transitions: Twist in development and metastasis. Cell 
2004, 118, 277-279.

47. Thiery, J.P. Epithelial-mesenchymal transitions in tumour progression. Nature reviews. Cancer 2002, 2, 442-454.

48. Zheng, H.; Li, W.; Wang, Y.; Xie, T.; Cai, Y.; Wang, Z.; Jiang, B. Mir-23a inhibits e-cadherin expression and is regulated by ap-1 and nfat 4 complex during fas-induced emt in gastrointestinal cancer. Carcinogenesis 2014, 35, 173-183.

49. Chung, H.W.; Lim, J.B. Role of the tumor microenvironment in the pathogenesis of gastric carcinoma. World journal of gastroenterology 2014, 20, 1667-1680.

50. Huang, L.; Xu, A.M.; Liu, S.; Liu, W.; Li, T.J. Cancer-associated fibroblasts in digestive tumors. World journal of gastroenterology 2014, 20, 17804-17818.

51. Ozdemir, B.C.; Pentcheva-Hoang, T.; Carstens, J.L.; Zheng, X.; Wu, C.C.; Simpson, T.R.; Laklai, H.; Sugimoto, H.; Kahlert, C.; Novitskiy, S.V., et al. Depletion of carcinoma-associated fibroblasts and fibrosis induces immunosuppression and accelerates pancreas cancer with reduced survival. Cancer cell 2014, 25, 719-734.

52. Duner, S.; Lopatko Lindman, J.; Ansari, D.; Gundewar, C.; Andersson, R. Pancreatic cancer: The role of pancreatic stellate cells in tumor progression. Pancreatology : official journal of the International Association of Pancreatology (IAP) ... [et al.] 2010, 10, 673-681.

53. Abe A.; Nagatsuma AK.; Higuchi Y.; Nakamura Y.; Yanagihara K.; Ochiai A. Site-specific fibroblasts regulate site-specific inflammatory niche formation in gastric cancer. Gastric Cancer. 2017 , 20, 92-103.

54. Comito, G.; Giannoni, E.; Segura, C.P.; Barcellos-de-Souza, P.; Raspollini, M.R.; Baroni, G.; Lanciotti, M.; Serni, S.; Chiarugi, P. Cancer-associated fibroblasts and $\mathrm{m} 2$-polarized macrophages synergize during prostate carcinoma progression. Oncogene 2014, 33, 2423-2431.

55. Gorchs, L.; Hellevik, T.; Bruun, J.A.; Camilio, K.A.; Al-Saad, S.; Stuge, T.B.; Martinez-Zubiaurre, I. Cancer-associated fibroblasts from lung tumors maintain their immunosuppressive abilities after high-dose irradiation. Frontiers in oncology 2015, 5, 87.

56. Hosein, A.N.; Livingstone, J.; Buchanan, M.; Reid, J.F.; Hallett, M.; Basik, M. A functional in vitro model of heterotypic interactions reveals a role for interferon-positive carcinoma associated fibroblasts in breast cancer. BMC cancer 2015, 15, 130.

57. Hu, C.; Wang, Z.; Zhai, L.; Yang, M.; Shan, L.; Chai, C.; Liu, M.; Wang, L. Effects of cancer-associated fibroblasts on the migration and invasion abilities of sgc-7901 gastric cancer cells. Oncology letters 2013, 5, 609-612.

58. Massani, M.; Stecca, T.; Fabris, L.; Caratozzolo, E.; Ruffolo, C.; Furlanetto, A.; Morton, S.; Cadamuro, M.; Strazzabosco, M.; Bassi, N. Isolation and characterization of biliary epithelial and stromal cells from resected human cholangiocarcinoma: A novel in vitro model to study tumor-stroma interactions. Oncology reports 2013, 30, 1143-1148.

59. Nagasaki, T.; Hara, M.; Nakanishi, H.; Takahashi, H.; Sato, M.; Takeyama, H. Interleukin-6 released by colon cancer-associated fibroblasts is critical for tumour angiogenesis: Anti-interleukin-6 receptor antibody suppressed angiogenesis and inhibited tumour-stroma interaction. British journal of cancer 2014, 110, 469-478.

60. Neesse, A.; Michl, P.; Frese, K.K.; Feig, C.; Cook, N.; Jacobetz, M.A.; Lolkema, M.P.; Buchholz, M.; Olive, K.P.; Gress, T.M., et al. Stromal biology and therapy in pancreatic cancer. Gut 2011, 60, 861-868.

61. Smith, N.R.; Baker, D.; Farren, M.; Pommier, A.; Swann, R.; Wang, X.; Mistry, S.; McDaid, K.; Kendrew, J.; Womack, C., et al. Tumor stromal architecture can define the intrinsic tumor response to vegf-targeted therapy. Clinical cancer research : an official journal of the American Association for Cancer Research 2013, 19, 6943-6956.

62. Evans, R.A.; Tian, Y.C.; Steadman, R.; Phillips, A.O. Tgf-beta1-mediated fibroblast-myofibroblast terminal differentiation-the role of smad proteins. Experimental cell research 2003, 282, 90-100.

63. Shukla, A.; Edwards, R.; Yang, Y.; Hahn, A.; Folkers, K.; Ding, J.; Padmakumar, V.C.; Cataisson, C.; Suh, K.S.; Yuspa, S.H. Clic4 regulates tgf-beta-dependent myofibroblast differentiation to produce a cancer stroma. Oncogene 2014, 33, 842-850.

64. Kojima, Y.; Acar, A.; Eaton, E.N.; Mellody, K.T.; Scheel, C.; Ben-Porath, I.; Onder, T.T.; Wang, Z.C.; Richardson, A.L.; Weinberg, R.A., et al. Autocrine tgf-beta and stromal cell-derived factor-1 (sdf-1) signaling drives the evolution of tumor-promoting mammary stromal myofibroblasts. Proceedings of the National Academy of Sciences of the United States of America 2010, 107, 20009-20014. 
65. Ishimoto, T.; Miyake, K.; Nandi, T.; Yashiro, M.; Onishi, N.; Huang, K.K.; Lin, S.J.; Kalpana, R.; Tay, S.T.; Suzuki, Y., et al. Activation of transforming growth factor beta 1 signaling in gastric cancer-associated fibroblasts increases their motility, via expression of rhomboid 5 homolog 2, and ability to induce invasiveness of gastric cancer cells. Gastroenterology 2017, 153, 191-204.e116.

66. Tsukada, T.; Fushida, S.; Harada, S.; Yagi, Y.; Kinoshita, J.; Oyama, K.; Tajima, H.; Fujita, H.; Ninomiya, I.; Fujimura, T., et al. The role of human peritoneal mesothelial cells in the fibrosis and progression of gastric cancer. International journal of oncology 2012, 41, 476-482.

67. Terai, S.; Fushida, S.; Tsukada, T.; Kinoshita, J.; Oyama, K.; Okamoto, K.; Makino, I.; Tajima, H.; Ninomiya, I.; Fujimura, T., et al. Bone marrow derived "fibrocytes" contribute to tumor proliferation and fibrosis in gastric cancer. Gastric Cancer 2015, 18, 306-313.

68. Sakaguchi, S. Regulatory t cells: Key controllers of immunologic self-tolerance. Cell 2000, 101, 455-458.

69. Zou, W. Regulatory t cells, tumour immunity and immunotherapy. Nature reviews. Immunology 2006, 6, 295-307.

70. Chen, W.; Jin, W.; Hardegen, N.; Lei, K.J.; Li, L.; Marinos, N.; McGrady, G.; Wahl, S.M. Conversion of peripheral $\mathrm{cd} 4+\mathrm{cd} 25$ - naive $\mathrm{t}$ cells to $\mathrm{cd} 4+\mathrm{cd} 25+$ regulatory $\mathrm{t}$ cells by tgf-beta induction of transcription factor foxp3. The Journal of experimental medicine 2003, 198, 1875-1886.

71. Tone, Y.; Furuuchi, K.; Kojima, Y.; Tykocinski, M.L.; Greene, M.I.; Tone, M. Smad3 and nfat cooperate to induce foxp3 expression through its enhancer. Nature immunology 2008, 9, 194-202.

72. Lu, X.; Liu, J.; Li, H.; Li, W.; Wang, X.; Ma, J.; Tong, Q.; Wu, K.; Wang, G. Conversion of intratumoral regulatory $\mathrm{t}$ cells by human gastric cancer cells is dependent on transforming growth factor-beta1. Journal of surgical oncology 2011, 104, 571-577.

73. Lebman, D.A.; Edmiston, J.S. The role of tgf-beta in growth, differentiation, and maturation of $b$ lymphocytes. Microbes and infection 1999, 1, 1297-1304.

74. Marcoe, J.P.; Lim, J.R.; Schaubert, K.L.; Fodil-Cornu, N.; Matka, M.; McCubbrey, A.L.; Farr, A.R.; Vidal, S.M.; Laouar, Y. Tgf-beta is responsible for nk cell immaturity during ontogeny and increased susceptibility to infection during mouse infancy. Nature immunology 2012, 13, 843-850.

75. Tanaka, H.; Shinto, O.; Yashiro, M.; Yamazoe, S.; Iwauchi, T.; Muguruma, K.; Kubo, N.; Ohira, M.; Hirakawa, K. Transforming growth factor beta signaling inhibitor, sb-431542, induces maturation of dendritic cells and enhances anti-tumor activity. Oncology reports 2010, 24, 1637-1643.

76. Chantry, D.; Turner, M.; Abney, E.; Feldmann, M. Modulation of cytokine production by transforming growth factor-beta. Journal of immunology (Baltimore, Md. : 1950) 1989, 142, 4295-4300.

77. Tsunawaki, S.; Sporn, M.; Ding, A.; Nathan, C. Deactivation of macrophages by transforming growth factor-beta. Nature 1988, 334, 260-262.

78. Mantovani, A.; Schioppa, T.; Porta, C.; Allavena, P.; Sica, A. Role of tumor-associated macrophages in tumor progression and invasion. Cancer metastasis reviews 2006, 25, 315-322.

79. Yamaguchi, T.; Fushida, S.; Yamamoto, Y.; Tsukada, T.; Kinoshita, J.; Oyama, K.; Miyashita, T.; Tajima, H.; Ninomiya, I.; Munesue, S., et al. Tumor-associated macrophages of the $\mathrm{m} 2$ phenotype contribute to progression in gastric cancer with peritoneal dissemination. Gastric Cancer 2016, 19, 1052-1065.

80. Gong, D.; Shi, W.; Yi, S.J.; Chen, H.; Groffen, J.; Heisterkamp, N. Tgfbeta signaling plays a critical role in promoting alternative macrophage activation. BMC immunology 2012, 13, 31.

81. Fridlender, Z.G.; Sun, J.; Kim, S.; Kapoor, V.; Cheng, G.; Ling, L.; Worthen, G.S.; Albelda, S.M. Polarization of tumor-associated neutrophil phenotype by tgf-beta: "N1" versus "n2" tan. Cancer cell 2009, 16, 183-194.

82. Hawinkels, L.J.; Ten Dijke, P. Exploring anti-tgf-beta therapies in cancer and fibrosis. Growth factors (Chur, Switzerland) 2011, 29, 140-152.

83. Shinto, O.; Yashiro, M.; Kawajiri, H.; Shimizu, K.; Shimizu, T.; Miwa, A.; Hirakawa, K. Combination effect of a tgf-beta receptor kinase inhibitor with 5 -fu analog s1 on lymph node metastasis of scirrhous gastric cancer in mice. Cancer science 2010, 101, 1846-1852.

84. Miao, Z.F.; Zhao, T.T.; Wang, Z.N.; Miao, F.; Xu, Y.Y.; Mao, X.Y.; Gao, J.; Wu, J.H.; Liu, X.Y.; You, Y., et al. Transforming growth factor-beta1 signaling blockade attenuates gastric cancer cell-induced peritoneal mesothelial cell fibrosis and alleviates peritoneal dissemination both in vitro and in vivo. Tumour biology : the journal of the International Society for Oncodevelopmental Biology and Medicine 2014, 35, 3575-3583.

85. Chauhan, V.P.; Martin, J.D.; Liu, H.; Lacorre, D.A.; Jain, S.R.; Kozin, S.V.; Stylianopoulos, T.; Mousa, A.S.; Han, X.; Adstamongkonkul, P., et al. Angiotensin inhibition enhances drug delivery and potentiates chemotherapy by decompressing tumour blood vessels. Nature communications 2013, 4, 2516. 
86. Sakurai, Y.; Yoshida, I.; Tonomura, S.; Sakai, W.; Nakamura, Y.; Imazu, H.; Matsubara, T.; Ochiai, M. Weekly administration of paclitaxel attenuated rectal stenosis caused by multiple peritoneal recurrence 8 years after the resection of gastric carcinoma. Gastric Cancer 2003, 6, 243-249.

87. Tsukada, T.; Fushida, S.; Harada, S.; Terai, S.; Yagi, Y.; Kinoshita, J.; Oyama, K.; Tajima, H.; Ninomiya, I.; Fujimura, T., et al. Low-dose paclitaxel modulates tumour fibrosis in gastric cancer. International journal of oncology 2013, 42, 1167-1174.

88. Tsukagoshi, S.; Hashimoto, Y.; Fujii, G.; Kobayashi, H.; Nomoto, K.; Orita, K. Krestin (psk). Cancer treatment reviews 1984, 11, 131-155.

89. Matsunaga, K.; Hosokawa, A.; Oohara, M.; Sugita, N.; Harada, M.; Nomoto, K. Direct action of a protein-bound polysaccharide, psk, on transforming growth factor-beta. Immunopharmacology 1998, 40, 219-230.

90. Yamaguchi, Y.; Minami, K.; Ohshita, A.; Kawabuchi, Y.; Noma, K.; Toge, T. Enhancing effect of ps-k on il-2-induced lymphocyte activation: Possible involvement of antagonistic action against tgf-beta. Anticancer research 2004, 24, 639-647.

91. Zhang, H.; Morisaki, T.; Matsunaga, H.; Sato, N.; Uchiyama, A.; Hashizume, K.; Nagumo, F.; Tadano, J.; Katano, M. Protein-bound polysaccharide psk inhibits tumor invasiveness by down-regulation of tgf-beta1 and mmps. Clinical E experimental metastasis 2000, 18, 343-352.

92. Ono, Y.; Hayashida, T.; Konagai, A.; Okazaki, H.; Miyao, K.; Kawachi, S.; Tanabe, M.; Shinoda, M.; Jinno, H.; Hasegawa, H., et al. Direct inhibition of the transforming growth factor-beta pathway by protein-bound polysaccharide through inactivation of smad2 signaling. Cancer science 2012, 103, 317-324.

93. Shinbo, T.; Fushida, S.; Tsukada, T.; Harada, S.; Kinoshita, J.; Oyama, K.; Okamoto, K.; Ninomiya, I.; Takamura, H.; Kitagawa, H., et al. Protein-bound polysaccharide k suppresses tumor fibrosis in gastric cancer by inhibiting the tgf-beta signaling pathway. Oncology reports 2015, 33, 553-558.

94. Suzawa, H.; Kikuchi, S.; Arai, N.; Koda, A. The mechanism involved in the inhibitory action of tranilast on collagen biosynthesis of keloid fibroblasts. Japanese journal of pharmacology 1992, 60, 91-96.

95. Martin, J.; Kelly, D.J.; Mifsud, S.A.; Zhang, Y.; Cox, A.J.; See, F.; Krum, H.; Wilkinson-Berka, J.; Gilbert, R.E. Tranilast attenuates cardiac matrix deposition in experimental diabetes: Role of transforming growth factor-beta. Cardiovascular research 2005, 65, 694-701.

96. Tao, Y.; Hu, L.; Li, S.; Liu, Q.; Wu, X.; Li, D.; Fu, P.; Wei, D.; Luo, Z. Tranilast prevents the progression of chronic cyclosporine nephrotoxicity through regulation of transforming growth factor beta/smad pathways. Transplantation proceedings 2011, 43, 1985-1988. 